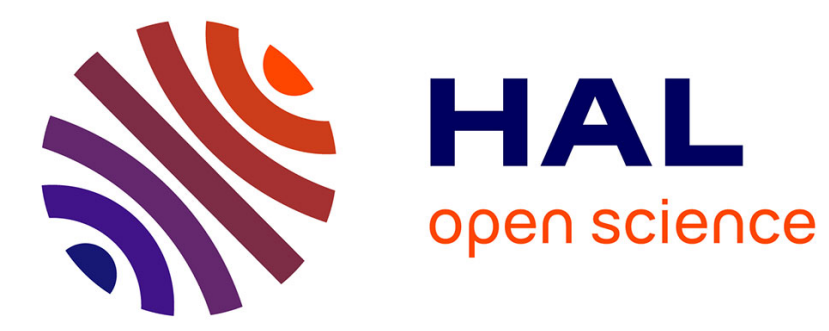

\title{
Predictions of carbon fixation during a bloom of Emiliania huxleyi as a function of the regulating inorganic species
}

Olivier Bernard, Antoine Sciandra, Sophie Rabouille

\section{To cite this version:}

Olivier Bernard, Antoine Sciandra, Sophie Rabouille. Predictions of carbon fixation during a bloom of Emiliania huxleyi as a function of the regulating inorganic species. Mathmod 2009 - 6th Vienna International Conference on Mathematical Modelling, Feb 2009, Vienne, Austria. hal-03523367

\section{HAL Id: hal-03523367 \\ https://hal.science/hal-03523367}

Submitted on 12 Jan 2022

HAL is a multi-disciplinary open access archive for the deposit and dissemination of scientific research documents, whether they are published or not. The documents may come from teaching and research institutions in France or abroad, or from public or private research centers.
L'archive ouverte pluridisciplinaire $\mathbf{H A L}$, est destinée au dépôt et à la diffusion de documents scientifiques de niveau recherche, publiés ou non, émanant des établissements d'enseignement et de recherche français ou étrangers, des laboratoires publics ou privés. 


\title{
Predictions of CARBON FIXATION DURING A BLOOM OF Emiliania huxleyi AS A FUNCTION OF THE REGULATING INORGANIC SPECIES
}

\author{
Olivier Bernard ${ }^{1}$, Antoine Sciandra ${ }^{2}$ and Sophie Rabouille ${ }^{2}$ \\ ${ }^{1}$ COMORE-INRIA, BP93, 06902 Sophia-Antipolis Cedex, France \\ ${ }^{2}$ LOV, UMR 7093, Station Zoologique, B.P. 28 06234, Villefranche-sur-mer, France \\ Corresponding author: Olivier Bernard \\ BP93, 06902 Sophia-Antipolis, France \\ Email: olivier.bernard@inria.fr
}

\begin{abstract}
Large scale precipitation of calcium carbonate in the oceans by coccolithophorids is a phenomenon that plays an important role in carbon sequestration. However, there is a controversy on the effect of an increase in atmospheric CO2 concentration on both calcification and photosynthesis of coccolithophorids. Indeed recent experiments, performed in conditions of nitrogen limitation, revealed that the associated fluxes may be slowed down, while other authors claim the reverse response. We have designed models to account for various scenarii of calcification and photosynthesis regulation in chemostat cultures of Emiliania huxleyi, based on different hypotheses of regulation mechanism. These models, which are kept at a general and generic level, consider that either carbon dioxide, bicarbonate, carbonate or $\mathrm{pH}$ is the regulating factor. These models are calibrated to predict the same carbon fluxes in nowadays pCO2, but they turn out to respond differently to an increase of $\mathrm{CO} 2$ concentration. Thus, we simulated a bloom of Emiliania huxleyi using the 4 considered regulation scenarii. For high biomass concentration, the coccolithophorids can significantly affect the inorganic carbon and the $\mathrm{pH}$ in their environment, thus leading to a feedback in their growth rate which is, depending on the model, positive or negative. It results that the prediction of the carbon fixed during the bloom varies by a factor 2 , depending on the assumed regulating mechanism hypothesized for growth and calcification.
\end{abstract}

\section{Introduction}

Phytoplankton uses light energy to build up organic cell components from inorganic carbon, and thus participates in the so-called "biologic pump" that traps $\mathrm{CO}_{2}$ from the atmosphere. In the world oceans, the activity of phytoplankton accounts for about $40 \%$ of the total, primary production on Earth. As $\mathrm{pCO}$ levels in the atmosphere rise, phytoplankton growth might be positively stimulated by an increased availability of dissolved $\mathrm{CO}_{2}$ in the upper oceans. However, a trade-off appears between $\mathrm{CO}_{2}$ being more available for growth, and a lowered $\mathrm{pH}$ due to the chemical equilibrium of the carbonate system and the consequent ocean acidification.

Coccolithophorids are particularly abundant in the oceans and thus play an important role in $\mathrm{CO}_{2}$ trapping [6]. These organisms are remarkable by the presence of solid, calcite structures called coccoliths that surround their cell. Coccolithophorids hence account for up to a third of the total, marine $\mathrm{CaCO}_{3}$ production. Such structures are relatively sensitive to $\mathrm{pH}$ and tend to dissolve when the water becomes too acidic. It is expected that increases in $\mathrm{pCO}_{2}$ will have direct consequences on the ability of these organisms to maintain their growth rate. As a corollary, acidification of the oceans due to atmospheric $\mathrm{pCO}_{2}$ increases could jeopardize their role as a $\mathrm{CO}_{2}$ pump. 
Hence, how Coccolithophorids may respond to shifts in global $\mathrm{pCO}_{2}$ is a critical question to be answered. However, if the photosynthesis mechanisms are well known, the effects of $\mathrm{pCO}_{2}$ changes, whether on photosynthesis or on calcification, are still subject to intense debates. In batch experiments, contradictory observations have been made, where increases in $\mathrm{pCO}_{2}$ either led to a decrease [8] or an increase [7] in calcification in Emiliana huxleyi, while photosynthesis was enhanced. Continuous cultures experiments in chemostats supported the hypothesis that both photosynthesis and calcification decrease [9].

In this paper, we investigate the relations between photosynthesis and calcification. We present a set of models, extended from [1], that integrate both phytoplankton growth and the carbonates system dynamics in the water. They were specifically designed to test several possible couplings and regulation mechanisms, assuming that calcification is regulated by one of the chemical species among $\mathrm{CO}_{2}, \mathrm{HCO}_{3}^{-}$and $\mathrm{CO}_{3}^{2-}$. The model, based on the representation of a cell quota, is a Droop-like model $[3,2,4]$ that we kept as general and generic as possible. Then, we add a fourth model where the calcite dissolution state acts as a regulating factor. To complete these biological models, a simplified representation of the carbonate system is proposed with three equations. Hence, knowing the concentration of dissolved inorganic carbon (DIC), the concentration in $\mathrm{Ca}^{2+}$ and considering the hypothesis of a constant concentration of the other ions in the water, the seawater model can predict the $\mathrm{pH}$ value and concentrations of $\mathrm{CO}_{2}, \mathrm{HCO}_{3}^{-}$and $\mathrm{CO}_{3}^{2-}$. This leads to four possible simplified models that can each represent a bloom of E.hux. These models bring two noteworthy results. We show that the predicted biomass can vary two-fold depending on the model, and that $\mathrm{pCO}_{2}$ has little influence on the bloom, due to the slow transfer of inorganic carbon at the atmosphere - seawater interface.

\section{Modelling growth and calcification}

\subsection{Biological aspects}

Here we present the mass flows in the model corresponding to nitrogen and carbon uptake.

Uptake of inorganic nitrogen (nitrate, denoted $S_{1}$ ) into the phytoplanktonic biomass (whose particulate nitrogen concentration is denoted $N$ ), can be represented by the following mass flow, where $\rho($.$) is the nitrate absorption rate:$

$$
S_{1} \stackrel{\rho(.) X}{\longrightarrow} N
$$

The flux of inorganic carbon into organic biomass $X$ and coccoliths $C$ is associated to a flux of calcium $\left(\mathrm{Ca}^{2+}\right.$, denoted $\left.S_{2}\right)$ :

$$
\frac{1-\alpha}{\alpha} S_{2}+\frac{1}{\alpha} D \quad \stackrel{\mu(.) X}{\longrightarrow} \quad \frac{1-\alpha}{\alpha} C+X
$$

Where $\mu($.$) is the photosynthesis rate.$

The next question is the modelling of both the nitrate absorption rate $\rho($.$) and the photosynthesis$ rate $\mu($.$) .$

Generally, the nitrate uptake rate is assumed to depend on external nitrate concentration $\mathrm{NO}_{3}$, following a Michaelis-Menten type equation [5].

The expression of the rate of inorganic carbon acquisition is more tricky; as shown by [3, 4], it must depend on the internal nitrogen quota $Q$. However, coccolithophorids photosynthesis and calcification are also sensitive to the DIC concentration, and there is a consensus to admit that $\mathrm{CO}_{2}$ is the substrate for photosynthesis while $\mathrm{HCO}_{3}^{-}$is the substrate of calcification. Therefore 
the regulation of growth and calcification can theoretically be triggered by $\mathrm{CO}_{2}$ or $\mathrm{HCO}_{3}^{-}$. We also examine the possibility that $\mathrm{CO}_{3}^{2-}$ is involved in the regulation process of inorganic carbon acquisition [1]. Finally, we also propose in this paper to consider the availability of calcium as a possible regulating factor of photosynthesis and calcification. In this last hypothesis, we examine the possibility that $\mu($.$) is regulated by \Omega$, the saturation state of calcite $\left(\mathrm{CaCO}_{3}\right)$ :

$$
\Omega=\frac{\left[\mathrm{Ca}^{2+}\right]\left[\mathrm{CO}_{3}^{2-}\right]}{K_{s p}}
$$

where the solubility constant yields $K_{s p}=5 \cdot 1510^{-7} \mathrm{~mol}^{2} \cdot L^{-2}$.

As a consequence, in the sequel we examine four possible models that only differ by the regulation mechanisms of inorganic carbon acquisition:

- $\mathrm{CO}_{2}$ is the regulating species, and thus $\mu\left(Q, C O_{2}\right)$ is an increasing function of both $Q$ and $\mathrm{CO}_{2}$.

- $\mathrm{HCO}_{3}^{-}$is the regulating species, and thus $\mu\left(\mathrm{Q}, \mathrm{HCO}_{3}^{-}\right)$is an increasing function of both $Q$ and $\mathrm{HCO}_{3}^{-}$.

- $\mathrm{CO}_{3}^{2-}$ is the regulating species, and thus $\mu\left(Q, C \mathrm{O}_{3}^{2-}\right)$ is an increasing function of both $Q$ and $\mathrm{CO}_{3}^{2-}$.

- $\Omega$ is the regulating species, and thus $\mu(Q, \Omega)$ is an increasing function of both $Q$ and $\Omega$.

To keep a general denomination, we denote $\mu_{p}\left(Q, D_{p}\right)$ the growth rate, where, depending on the model $\mathscr{M}_{p}, \mathrm{D}_{p}$ has to be chosen among $\mathrm{CO}_{2}, \mathrm{HCO}_{3}^{-}, \mathrm{CO}_{3}^{2-}$ and $\Omega$.

For simulation purposes, we represent the $N O_{3}$ uptake rate [5], $\rho\left(S_{1}\right)=\rho_{m} S_{1} /\left(S_{1}+k_{N}\right)$, where $\rho_{m}$ and $k_{N}$ are the maximum uptake rate and the half-saturation constant, respectively. Based on the Droop model $[3,4]$, the net growth rate may be written as:

$$
\mu\left(Q, D_{p}\right)=\bar{\mu}\left(1-\frac{k_{Q}}{Q}\right) \frac{D_{p}}{D_{p}+k_{D_{p}}}-R
$$

where $k_{Q}, \bar{\mu}$ and $k_{D_{p}}$ are respectively the subsistence internal quota, the maximum hypothetical growth rate and the half-saturation constant for the chosen regulating species. $R$ is the respiration rate (supposed to be constant).

\subsection{Seawater modelling}

In order to compute $\mathrm{CO}_{2}, \mathrm{HCO}_{3}^{-}, \mathrm{CO}_{3}^{2-}$ and $\Omega$ from $\mathrm{D}$ and $\mathrm{S}_{2}$, classical equations of the seawater carbonate system must be considered [10].

The carbonate alkalinity $(\mathrm{CA})$ represents the electric charges carried in the carbonate system:

$$
\mathrm{CA}=\left[\mathrm{HCO}_{3}^{-}\right]+2\left[\mathrm{CO}_{3}^{2-}\right]
$$

The total alkalinity (TA) is defined by (see [10] for more details) :

$$
\mathrm{TA}=\mathrm{CA}+\left[\mathrm{B}(\mathrm{OH})_{4}^{-}\right]+[\mathrm{OH}-]-\left[\mathrm{H}^{+}\right]
$$

We denote $\lambda=T A-2\left[\mathrm{Ca}^{2+}\right]=T A-2 S_{2}$. In a first approximation, the ions that most contribute to $\lambda$ depend on the salinity and remain constant. 
Following the previous considerations, carbonate alkalinity thus only depends on calcium: $C A=$ $\lambda-\lambda_{0}+2 S_{2}$ (where, in a first approximation, $\lambda_{0}=\left[B(\mathrm{OH})_{4}^{-}\right]+\left[\mathrm{OH}^{-}\right]-\left[\mathrm{H}^{+}\right]$remains constant compared to $\mathrm{CA}$ ). In order to compute the $\left[\mathrm{HCO}_{3}^{-}\right]$and $\left[\mathrm{CO}_{3}^{2-}\right]$ concentrations, we use the dissociation constants of the carbon dioxide $\left(\mathrm{K}_{1}\right)$ and bicarbonate $\left(\mathrm{K}_{2}\right)$ (the proton concentration, $\left[H^{+}\right]$, will be denoted $\left.h\right)$ :

$$
K_{1}=\frac{h\left[\mathrm{HCO}_{3}^{-}\right]}{\left[\mathrm{CO}_{2}\right]} \text { and } K_{2}=\frac{h\left[\mathrm{CO}_{3}^{2-}\right]}{\left[\mathrm{HCO}_{3}^{-}\right]}
$$

The total dissolved inorganic carbon (D ) is defined as:

$$
\mathrm{D}=\left[\mathrm{HCO}_{3}^{-}\right]+\left[\mathrm{CO}_{3}^{2-}\right]+\left[\mathrm{CO}_{2}\right]
$$

Note that, in the considered $\mathrm{pH}$ range, we have $\left[\mathrm{HCO}_{3}^{-}\right]>>\left[\mathrm{CO}_{3}^{2-}\right]>>\left[\mathrm{CO}_{2}\right]$ (see for example $[10])$. It follows that bicarbonate is the main carbon species in the bicarbonate system:

$$
\left[\mathrm{HCO}_{3}^{-}\right] \simeq \mathrm{D}
$$

We deduced from equations (5) and (8), in the considered $\mathrm{pH}$ range:

$$
\left[\mathrm{CO}_{3}^{2-}\right] \simeq C A-D
$$

With this approximation, we can now compute the following ratio: $r=\frac{D}{C A}$, using equations (5), (8) and (7), we get:

$$
r=\frac{h+K_{2}+h^{2} / K_{1}}{h+2 K_{2}}
$$

It follows that $h$ can be computed as a function of $r$ :

$$
h=u(r)=\left(-1+r+\sqrt{(1-2 r)\left(1-4 K_{2} / K_{1}\right)+r^{2}}\right) \frac{K_{1}}{2}
$$

Now using equations (7) and (5) we can compute the exact $\mathrm{CO}_{2}$ concentration:

$$
\left[C O_{2}\right]=\frac{C A}{K_{1}} \frac{h^{2}}{h+2 K_{2}}=C A v(r)=\psi\left(S_{2}, D\right)
$$

This simplified seawater modelling allowed a mathematical analysis of coccolithophorids models [1]. However, in the simulation, we used a more accurate model that does not make any approximation. The used Matlab code is a supplement to [10].

\section{Modelling of a E. huxleyi bloom in a mixed layer}

In summer, increasing temperatures lead to a density gradient that stabilizes the water column, which then stratifies. The surface layer remains mixed over a generally shallow depth (in the order of $20 \mathrm{~m}$ ) and to keep the model as simple as possible, we assume an homogeneous distribution. We simulated the growth of coccolithophorids in this mixed layer, as represented in Fig. 1. $\mathrm{CO}_{2}$ concentration in the water equilibrates with that in the atmosphere, following the difference in concentration between the two compartments and according to the diffusion coefficient $K_{L} a$. 


\begin{tabular}{|c|c|c|}
\hline Parameters & Values & Units \\
\hline $\mathrm{S}_{10}$ & 50 & $\mu \operatorname{molN} . L^{-1}$ \\
\hline $\mathrm{S}_{20}$ & 10.4 & mmolCa. $L^{-1}$ \\
\hline $\mathrm{D}_{0}$ & 1.77 & mmolC. $L^{-1}$ \\
\hline$K_{L} a$ & 0.06 & $d^{-1}$ \\
\hline$\rho_{m}$ & 100.19 & MmolN.mmolC ${ }^{-1} \cdot d^{-1}$ \\
\hline$k_{Q}$ & 32.29 & MmolN.mmolC ${ }^{-1}$ \\
\hline$k_{S_{1}}$ & 0.038 & $\mu m o l N . L^{-1}$ \\
\hline $\mathrm{K}_{1}$ & $1.39210^{-6}$ & mmol. $L^{-1}$ \\
\hline $\mathrm{K}_{2}$ & $1.18910^{-9}$ & mmol. $L^{-1}$ \\
\hline $\mathrm{K}_{H}$ & 36.7 & $\mathrm{mmolCO}_{2} \cdot L^{-1} \cdot \mu \mathrm{atm}$ \\
\hline$\alpha$ & 0.53 & - \\
\hline$\lambda$ & $-17.31^{3}$ & $\operatorname{mmol} . L^{-1}$ \\
\hline$\lambda_{0}$ & $0.086^{3}$ & $\operatorname{mmol} . L^{-1}$ \\
\hline$K_{\text {diss }}$ & 0.15 & $d^{-1}$ \\
\hline$K_{d}$ & 0.8 & $d^{-1}$ \\
\hline$K_{\text {sed }}$ & 0.15 & $d^{-1}$ \\
\hline$R$ & 0.01 & $d^{-1}$ \\
\hline
\end{tabular}

Table 1: Values of the model parameters.

Diffusion at the ocean surface is generated by wind stress, and so much lower $K_{L} a$ values must be considered here compared to e.g. bioreactors. That is, the low value $\left(0.06 \mathrm{day}^{-1}\right)$ used in the model is representative of the natural environment. As a corollary, it is expected that high biomasses may draw down the DIC pool faster than it is renewed. In the water, $\mathrm{CO}_{2}$ equilibrates with $\mathrm{HCO}_{3}^{-}$and $\mathrm{CO}_{3}^{2-}$. The $\mathrm{CO}_{2}$ pool in the water is also affected by the coccolithophorids activity, being fuelled by respiration and consumed through the growth process (see (2)). The model simulates a nitrate uptake limited by the availability of $\mathrm{NO}_{3}$, as illustrated by (1), while growth and coccoliths formation depend on the availability of both $\mathrm{Ca}^{2+}$ and $\mathrm{CO}_{3}^{2-}$ (see $(2)$ ). $\mathrm{NO}_{3}$ and $\mathrm{Ca}^{2+}$ are provided by upwelling of deeper waters underlying the mixed layer (with an exchange rate $K_{d}$ ). The water acidity affects the coccoliths persistence; we accounted for a possible dissolution of coccoliths, whose rate is dependent upon $\mathrm{pH}$ and represented by $\frac{K_{\text {diss }}}{\Omega} \mathrm{C}$. Settlement of calcite (detached coccoliths) is represented through $\mathrm{CaCO}_{3}$ sinking below the mixed layer.

Model equations can then be directly deduced from the mass flows (1) and (2). $D_{p}$ is the regulating factor (among $\mathrm{CO}_{2}, \mathrm{HCO}_{3}^{-}, \mathrm{CO}_{3}^{2-}$ and $\Omega$ ) assumed to regulate both photosynthesis and calcification. The system of equations reads:

$$
\begin{aligned}
\dot{S}_{1} & =K_{d}\left(S_{10}-S_{1}\right)-\rho\left(S_{1}\right) X \\
\dot{Q} & =\rho\left(S_{1}\right)-\mu\left(Q, D_{p}\right) Q \\
\dot{X} & =-K_{d} X+\mu\left(Q, D_{p}\right) X-R X-K_{\text {sed }} X \\
\dot{C} & =-K_{d} C+\frac{1-\alpha}{\alpha} \mu\left(Q, D_{p}\right) X-K_{\text {sed }} C-\frac{K_{\text {diss }}}{\Omega} C \\
\dot{D} & =K_{d}\left(D_{0}-D\right)-\frac{1}{\alpha} \mu\left(Q, D_{p}\right) X+R X-K_{L} a\left(\psi\left(S_{2}, D\right)-K_{H} p C O_{2}\right)+\frac{K_{\text {diss }}}{\Omega} C \\
\dot{S}_{2} & =K_{d}\left(S_{20}-S_{2}\right)-\frac{1-\alpha}{\alpha} \mu\left(Q, D_{p}\right) X
\end{aligned}
$$




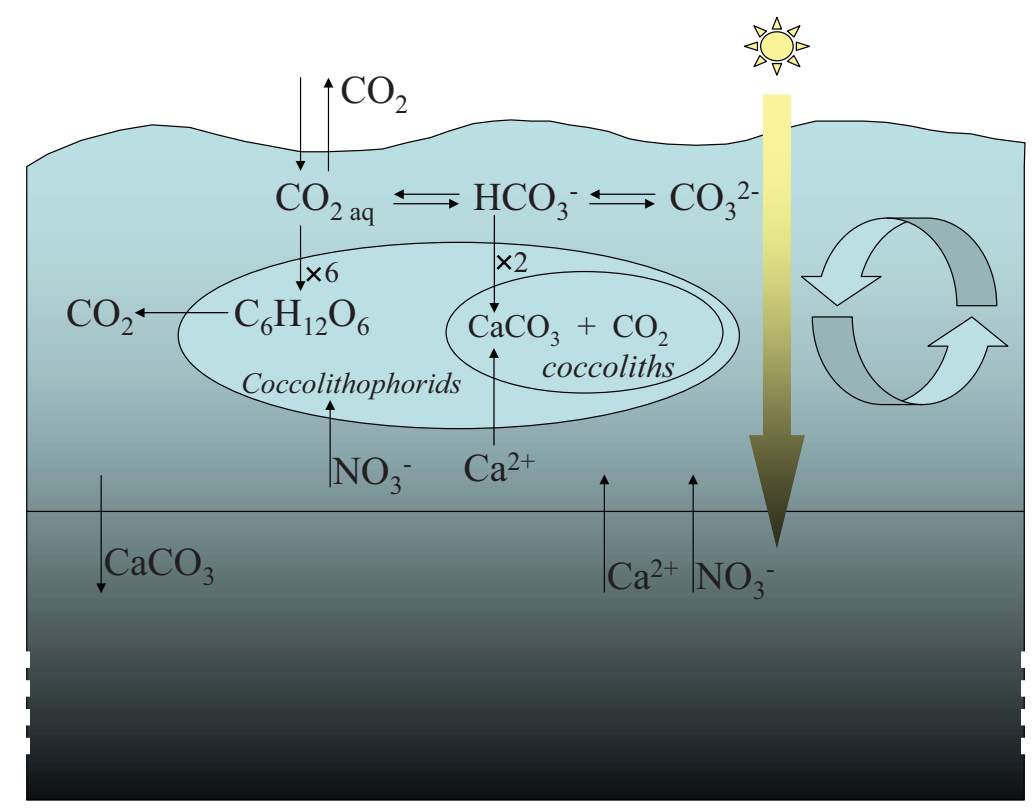

Figure 1: Schematic diagram of the well mixed upper ocean represented by the model.

Where the exchange rate at the thermocline level is $K_{d}$, the sedimentation rate is $K_{\text {sed }}$, and the coccoliths dissolution rate is $\frac{K_{\text {diss }}}{\Omega}$.

The specific rate of carbon fixation is described as an increasing function of $Q$ and $D_{p}$, which allows a generic analysis of the model [1]. Depending on the choice for $D_{p}$, four different models are obtained, based on three different hypotheses on the mechanisms driving both photosynthesis and calcification. The models have been calibrated in order to predict the same carbon fluxes in nowadays $\mathrm{pCO}_{2}$, on the basis on available experimental results [1]. Parameter values are presented in Tables 1 and 2 .

The model analysis proposed in [1] demonstrates that $\mathscr{M}_{p}$ models where $D_{p}$ is either $\mathrm{CO}_{2}$ or $\mathrm{HCO}_{3}^{-}$support the results of [7], while models where $\mathrm{CO}_{3}^{2-}$ or $\Omega$ is the regulating factor support the results obtained by [9]. Last, none of these models allowed a qualitative prediction of the experimental results reported by [8]. Different model hypotheses were then required to reproduce these observations: photosynthesis had to be regulated by either $\mathrm{CO}_{2}$ or $\mathrm{HCO}_{3}^{-}$while calcification was driven by $\mathrm{CO}_{3}^{2-}$ or $\Omega[1]$.

\begin{tabular}{lccccl}
\hline Parameters & $\mathrm{CO}_{3}^{2-}$ & $\mathrm{HCO}_{3}^{-}$ & $\mathrm{CO}_{2}$ & $\Omega$ & Units \\
$k_{D_{p}}$ & 0.076 & 1.65 & 0.01 & $1.53^{\dagger}$ & $\mu$ molC.L \\
$\bar{\mu}$ & 2.83 & 3.76 & 3.24 & 2.88 & $d^{-1}$ \\
\hline
\end{tabular}

Table 2: Kinetics parameters depending on the chosen model. $\left({ }^{\dagger}\right.$ unitless for $\left.k_{\Omega}\right)$ 
a)

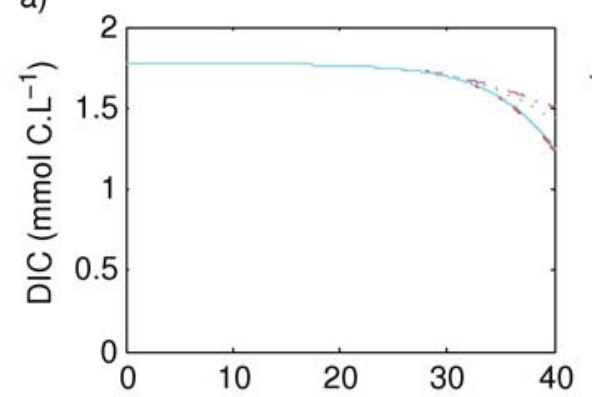

c)

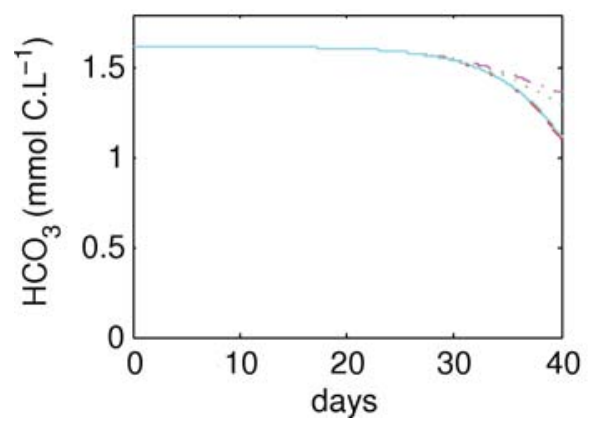

b)

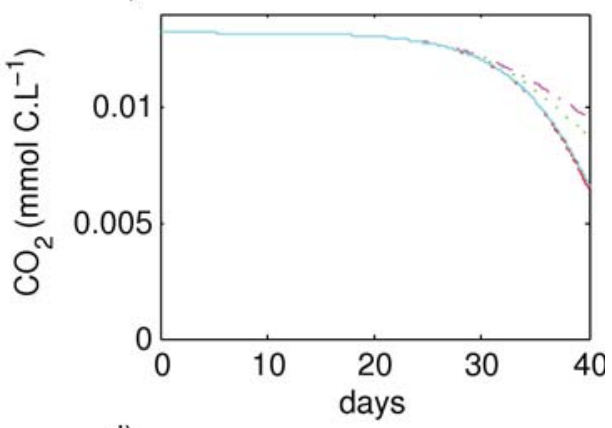

d)

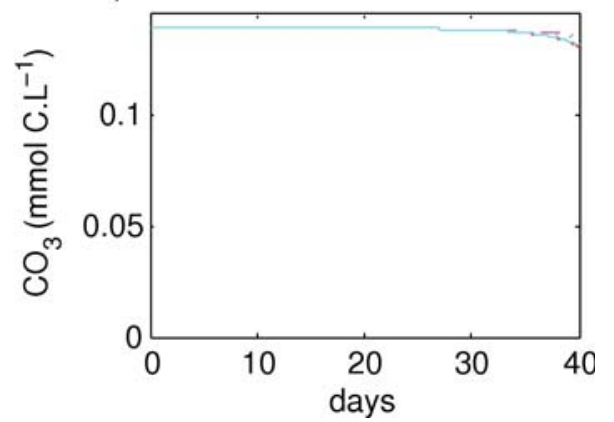

Figure 2: Depending on the considered choice of $\mathrm{D}_{\mathrm{p}}\left(\mathrm{CO}_{2}: \mathrm{L}_{-}, \mathrm{HCO}_{3}^{-} \mathrm{:} \ldots, \mathrm{CO}_{3}^{2-}: \mathrm{Z}_{3}, \Omega\right.$ : ), evolution of the various compartment of inorganic carbon. The model where $\mathrm{HCO}_{3}^{-}$is the regulating factor shows the strongest impact on the inorganic carbon.

\section{Model simulation}

We used each of these models to simulate a large development (bloom) of Emiliania huxleyi. Phytoplankton cells are assumed to grow in a homogeneous layer, where aqueous $\mathrm{CO}_{2}$ is in equilibrium with the atmosphere. The considered, realistic $K_{L} a$ being rather low, the time necessary to supply inorganic carbon to the cells can be long. This can explain the significantly different behaviour between the 4 scenarii (Fig. 2). Indeed, it turns out that, for high biomass concentrations, the coccolithophorids can significantly draw down the inorganic carbon and thus affect the $\mathrm{pH}$ in their environment. Depending on the model, the simulated mechanisms induce a positive (in the models with $\mathrm{CO}_{3}^{2-}$ or $\Omega$ as regulating factor) or negative (in models with $\mathrm{CO}_{2}$ or $\mathrm{HCO}_{3}^{-}$) feedback on the growth rate. It results that the prediction of carbon fixed during the bloom formation can vary by a factor up to 2 , depending on the assumed regulating mechanism hypothesized for growth and calcification (Fig. 3). The simulations with $\Omega$ as regulating factor make little difference to that with $\mathrm{CO}_{3}^{2-}$. Such result can be explained by the fact that changes in $\mathrm{Ca}^{2+}$ concentrations being small, $\Omega$ fluctuations are similar to that of $\mathrm{CO}_{3}^{2-}$.

When introducing a coccoliths dissolution term, model results remain close to that obtained without dissolution rate. Hence, the rate of coccoliths dissolution stayed low. This can be explained by the remarkable stability of $\mathrm{CO}_{3}^{2-}$ whose concentration variation did not exceed $10 \%$. Indeed the decrease of $\mathrm{CO}_{3}^{2-}$ due to exhaustion of total inorganic carbon is compensated by the $\mathrm{pH}$ increase that favors the form $\mathrm{CO}_{3}^{2-}$ to the detriment of $\mathrm{HCO}_{3}^{-}$.

Last, investigating the influence of different surface $\mathrm{p} \mathrm{CO}_{2}$ revealed very little impact on growth. An increase from $380 \mathrm{ppm}$ to $600 \mathrm{ppm}$ only modified the total production by about $2 \%$. At 

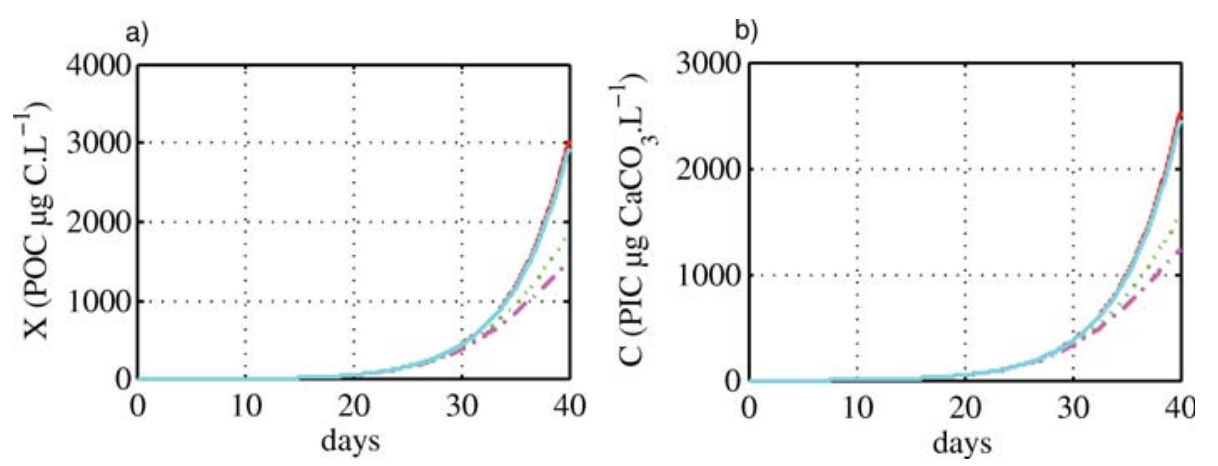

Figure 3: Amount of inorganic carbon which is fixed through photosynthesis (a) and calcification

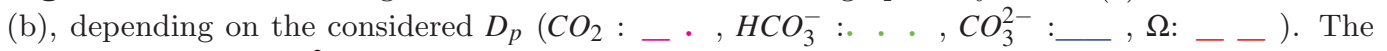
models where $D_{p}=C O_{3}^{2-}$ or $D_{p}=\Omega$ predict much higher carbon fluxes.

the air/sea interface, low $K_{L} a$ values limit the increase in dissolved $\mathrm{CO}_{2}$ concentrations and, as a corrolary, short time scales (month) changes in $\mathrm{pCO}_{2}$ in the water do not reflect that in the atmosphere. Consequently, model results suggest that biomass production remains relatively insensitive to changes in atmospheric $\mathrm{pCO}_{2}$.

\section{Conclusion}

This study stresses how a correct identification of the chemical species that drive(s) calcification and photosynthesis processes is critical to accurately predict a bloom of coccolithophorids and the consequent amount of carbon withdrawn from the atmosphere and trapped into the deep ocean. The model results reveal a striking difference in the predicted biomass increase when the saturation state $\Omega$ (or equivalently $\mathrm{CO}_{3}^{2-}$ ) is the regulating factor.

In the configuration of a low air/sea exchange, model results suggest that increased $\mathrm{pCO}_{2}$ in the air show very little impact on growth. Due to the exhaustion of the DIC pool by the high biomasses formed during the bloom and low transfer coefficient, changes in surface $\mathrm{pCO}_{2}$ hardly affect the bloom intensity. Such paradoxical transient behaviour only apply to off shore marine systems. Coastal, shallow ecosystems may present higher diffusion rates and model results then suggest a higher impact of surface $\mathrm{pCO}_{2}$ on growth: under conditions of higher $K_{L} a$ values, the $\mathrm{CO}_{2}$ resupply to the water participates in enhancing bloom formations for models regulated by $\mathrm{CO}_{2}$ or $\mathrm{HCO}_{3}^{-}$and shows a positive effect on growth, while the opposite behaviour is observed for models regulated by $\mathrm{CO}_{3}^{2-}$ or $\Omega$.

Acknowledgements: The authors benefited from the support of the BOOM project (Biodiversity of Open Ocean Microcalcifiers) funded by the French National Research Agency (ANR), and of the European FP7 Integrated Project EPOCA (European Project on OCean Acidification).

\section{References}

[1] O. Bernard, A.Sciandra, and S. Madani. Multimodel analysis of the response of the coccolithophore Emiliania huxleyi to an elevation of $\mathrm{pCO}_{2}$ under nitrate limitation . Ecol. Model., 211:324-338, 2008.

[2] D. Burmaster. The unsteady continuous culture of phosphate-limited monochrisis lutheri 
droop : Experimental and theoretical analysis. Journal of Experimental Marine Biology and Ecology, 39 (2):167-186, 1979.

[3] M. R. Droop. Vitamin B12 and marine ecology. IV. the kinetics of uptake growth and inhibition in Monochrysis lutheri. J. Mar. Biol. Assoc., 48(3):689-733, 1968.

[4] M. R. Droop. 25 years of algal growth kinetics, a personal view. Botanica marina, 16:99$112,1983$.

[5] R. C. Dugdale. Nutrient limitation in the sea: dynamics, identification and significance. Limnol. Oceanogr., 12:685-695, 1967.

[6] M. Frankignoulle, C. Canon, and J. P. Gattuso. Marine calcification as a source of carbon dioxide: positive feedback of increasing atmospheric co2. Limnol Oceanogr, 39:458-462, 1994.

[7] M. D. Iglesias-Rodriguez, Paul R. Halloran, Rosalind E. M. Rickaby, Ian R. Hall, Elena Colmenero-Hidalgo, John R. Gittins, Darryl R. H. Green, Toby Tyrrell, Samantha J. Gibbs, Peter von Dassow, Eric Rehm, E. Virginia Armbrust, and Karin P. Boessenkool. Phytoplankton calcification in a high-co2 world. Science, 2008.

[8] U. Riebesell, I. Zondervan, B. Rost, P.D. Tortell, R. E. Zeebe, and F. M. M. Morel. Reduced calcification of marine plankton in response to increased atmospheric co2. Nature, 407:364$367,2000$.

[9] A. Sciandra, J. Harlay, D. Lefèvre, R. Lemée, P. Rimmelin, M. Denis, and J.-P. Gattuso. Response of coccolithophorid emiliania huxleyi to elevated partial pressure of co2 under nitrogen limitation. Mar. Ecol. Prog. Ser., 261:111-122, 2003.

[10] R. E. Zeebe and D. Wolf-Gladrow. $\mathrm{CO}_{2}$ in seawater: equilibrium, kinetics, isotopes. Elsevier, 2003. 